\title{
OS DONOS DO PODER EM CAMPO LARGO: QUEM SÃO?
}

\author{
Vanderlei Hermes Machado ${ }^{2}$ \\ Milene Zerek Capraro ${ }^{3}$
}

- Enviado em 16/04/2016

- Aprovado em 20/05/2016

\section{RESUMO}

O trabalho tem por objetivo a identificação dos principais agentes políticos e econômicos da cidade de Campo LargoPR, no ano de 2015. Suas genealogias, trajetórias políticas e econômicas, comporão o estudo que visa fornecer elementos para a compreensão da dinâmica político social desta localidade. "Os donos do poder em Campo Largo", também almeja auxiliar o NEP - Núcleo de Estudos Paranaenses - na composição de um acervo sociológico sobre o Paraná, no que tange aos personagens da vida política, histórica e econômica deste estado.

Palavras-chave: Campo Largo. Genealogia. Política paranaense.

\section{INTRODUÇÃO}

Analisar os "donos do poder" no município de Campo Largo no ano de 2015, implica necessariamente na compreensão de sua gênese sócio-econômica, na medida em que consideramos sua constituição como parte integrante do cenário de atuação de seus principais agentes políticos numa perspectiva histórico-social. Nesse contexto, identificamos a atuação de vários membros das famílias politicamente atuantes no município, que exibem uma tradição de continuidade eleitoral, tanto no Poder Executivo, como no Poder Legislativo.

\footnotetext{
${ }^{1}$ Uma versão preliminar desse trabalho foi apresentada no GT1: INSTITUIÇÕES E PODER: PARENTESCOS E GENEALOGIAS do VII Seminário Nacional de Sociologia e Política da UFPR realizado de 11 a 13 de maio de 2016 em Curitiba.

${ }^{2}$ Licenciado e Mestre em Ciências Sociais pela Universidade Federal do Paraná. Professor de Sociologia da rede estadual de Ensino Médio. Doutorando em Sociologia pela Universidade Federal do Paraná. Endereço eletrônico: vanderleihermes@yahoo.com.br

${ }^{3}$ Doutoranda em Ciencias Sociais pela UFPR 2013, Mestre em Ciência Jurídica pela UNIVALI - Itajaí/SC 2010, Especialista em Direito Empresarial - IBEJ-Curitba /PR 2002, Licenciada em Direito - Instituto Superior do Litoral do Paraná - Paranaguá/PR 2006 . Graduada em Ciência Jurídica pela Pontifícia Universidade Católica do Paraná 1998. Atualmente é Advogada , Professora de Graduação e Pós Graduação. Endereço eletrônico: milenezerek@gmail.com 
De acordo com esta premissa inicial e visando o levantamento de contextos sócioeconômicos do município, relevante se faz nos reportarmos a um elemento importante de sua constituição, o caminho denominado Peabiru ${ }^{4}$. Esta trilha muita antiga, pré-cabralina, partia da região de Cananéa, situada na costa sul de São Paulo, por Serra Negra, e prosseguia através do Paraná, passando pelos campos de Curitiba e Campo Largo, e pelas cabeceiras dos seus rios Açungui e Ribeirinha. Foi durante longo tempo, a principal via de movimentação de bandeirantes, viajantes, aventureiros, cujo objetivo principal teria sido a corrida em busca do ouro. Neste âmbito, consideramos relevante ressaltar a Bandeira empreendida pelo primeiro administrador das Minas do Sul do Brasil, Eleodoro D`Ebano Pereira. Esta Bandeira, realizada no período compreendido entre 1645 e 1647, percorreu diversas zonas auríferas do Paraná, inclusive Campo Largo, mais especificamente na região conhecida como Itambé, nas cabeceiras dos rios Açungui, Ribeirinha e Tibagi. $^{5}$

Atribui-se ao Capitão Antonio Luiz Lamin, conhecido como "O Tigre", a descoberta de minas de ouro no Itambé, por ocasião da expedição realizada em 1649, chefiada por Dom Rodrigo de Castel Blanco, Administrador Geral das Minas de Paranaguá. ${ }^{6}$ Esta localidade serviria como um ponto de passagem quase obrigatório, para aqueles que vinham do Sul de São Paulo, em particular Itanhaên e Cananéa, devido as duas vias existentes que para lá conduziam, uma via natural em Campo Largo, margeando o rio Açungui, e a trilha indígena conhecida como Caminho Peabiru. Provavelmente, foi à primeira região de Campo Largo habitada pelo homem branco, em sua maioria garimpeiros, proveniente da região de São Vicente, no Estado de São Paulo. Constituindo pequenos núcleos denominados "arraiais", 7 sua durabilidade muitas vezes estaria diretamente ligada, ao tempo de duração da exploração das minas de ouro.

Outro elemento concomitante a fase econômica da exploração do ouro, teria sido a atividade denominada tropeirismo, que consistia na comercialização de tropas de animais (bois, vacas,

\footnotetext{
4 “A palavra 'Peabiru' significa caminho forrado, cujo radical 'pé' ou 'apé' significa trilha, caminho, em Tupi. Em busca de um acesso às riquezas incas, em 1524 o português Aleixo Garcia, à partir do litoral de Santa Catarina, e rumando para oeste, seguindo o caminho traçado pelos índios, chegou à região de Assunção, no Paraguai. Depois de diversas peripécias e confrontos com inúmeras tribos uma pequena parte de sua expedição retornou com peças de ouro e prata tomadas dos Incas. Aleixo Garcia, antes mesmo dos espanhóis, foi o primeiro europeu a fazer contato com os Incas, e a penetrar o interior do Brasil e do Paraguai”. (Disponível em: 〈http://www.peabiru.org.br/ins_peabiru.htm>. Acesso em: 06/07/2015.)
}

${ }^{5}$ BARBOSA, João Augusto de Almeida. Campo Largo desde 1500. Campo Largo: Casa da Cultura, 1994.p.05.

${ }^{6}$ Ibid., p. 20

${ }^{7}$ POVOADO, LUGAREJO. In: MODERNO dicionário brasileiro. Curitiba: Ed. Educacional Brasileira, 1979. v.I.. 
cavalos, mulas, entre outros), vindas principalmente do sul do Brasil, e de países como Argentina e Uruguai, direcionadas aos mercados consumidores localizados principalmente em São Paulo (Sorocaba), Minas Gerais e Rio de Janeiro. Segundo Oney Barbosa Borba, ${ }^{8}$ o tropeirismo enquanto um ciclo na evolução dos meios de transportes terrestres, dependia de aspectos da exploração econômica. Quando o interesse principal recaia sobre a mineração, ele vinculou-se ao transporte de gado e mulas para alimentação, e também ao deslocamento de mineiros; ao enfocar a atividade produtora dos canaviais, como a produção do açúcar, ele satisfaria exigências relativas ao transporte de cargas desse produto. Aos poucos, tal tendência desapareceria com o emprego de maquinário como meio de transporte da produção. Devemos, entretanto, ressaltar o caráter de incentivo à formação de povoados pela atividade tropeira. Embora esta tenha sido essencialmente itinerante, as invernadas, ou seja, a ocasião em que a tropa e os tropeiros necessitavam de repouso, produziam aglomeração e consequentemente, explorações comerciais advindas desse processo.

Em Campo Largo identificamos a participação de alguns dos personagens que possuíam, no rol das suas atividades econômicas, o tropeirar. Entre eles o Major Antonio de Paula Xavier, que além de ser tropeiro, viajando grande parte das Províncias do Rio de Janeiro, Minas Gerais, São Paulo, Santa Catarina e Rio Grande do Sul, também era ervateiro, proprietário de engenho de farinha de mandioca e de fábrica de velas, vinho e aguardente de mel de abelhas. Foi Vereador da Câmara Municipal em $1871 ;^{9}$ o Tenente José Maria Padilha, proprietário da antiga fazenda dos Carlos ou do Registro Velho, localizada às margens do rio Iguaçu, nos limites com a Lapa; ${ }^{10}$ o Tenente Domingos Antonio da Cunha, teria sido negociante de bestas durante quinze anos, comprando-as na Província do Rio Grande do Sul, para revendê-las na feira de Sorocaba, em São Paulo; ${ }^{11}$ tal procedimento também era realizado por Francisco das Chagas Mendes, juntamente com seu sobrinho, o Capitão José Olintho Mendes de Sá, conhecido em Campo Largo como "Jojica”; foi proprietário das fazendas de gado Santo Amaro, em Castro, e Águas Belas, em São José dos Pinhais. $^{12}$

\footnotetext{
${ }^{8}$ BORBA, Oney Barbosa. Tropeirismo paranaense. Boletim do Instituto Histórico, Geográfico e Etnográfico Paranaense, Curitiba, v.XLVII, p. 107, 1990.

${ }^{9}$ SOARES, op. cit., p. 379.

${ }^{10}$ Ibid., p. 398.

${ }^{11}$ Ibid., p. 385.

${ }^{12}$ Ibid., p. 388 e 392.
} 
Outra atividade de relevância econômica, tanto para Campo Largo como para o Paraná, foi a ervateira. Considerada como uma contribuição nativa dos indígenas americanos, sendo utilizada pelo grande grupo Guarani, sua presença seria anterior a chegada dos europeus no século XVI e início do XVII; originária das folhas de uma árvore, sua ocorrência natural abrangeria o norte do Rio Grande do Sul, os planaltos de Santa Catarina e Paraná, o sul do Mato Grosso do Sul, o Paraguai, e a região das Missões, na Argentina. ${ }^{13}$ Ganharia destaque com a ocupação espanhola do Paraguai e da região de Guairá através dos jesuítas, que percebendo o seu uso nos hábitos alimentares de colonos e indígenas, teriam iniciado a estruturação de sua economia. Nesse sentido, a difusão do consumo do mate pelos domínios espanhóis, constituídos pelas reduções jesuíticas, povoações do Paraná, estuário do rio da Prata e da vertente andina, compreendida pelo Chile, Peru e a atual Bolívia, a produção e comercialização da erva-mate se mostrou bastante lucrativa. Com o despovoamento e a destruição das Missões do Guairá, os bandeirantes portugueses ganhariam acesso às regiões naturais da erva-mate no Paraná, conhecida entre eles pelo termo "congonha", de origem caiganqui ou tupi. ${ }^{14}$ Com a ocupação e posterior povoamento luso-brasileiro, através de Paranaguá e do planalto de Curitiba, teríamos as primeiras notícias acerca da erva-mate no Brasil. ${ }^{15}$ Nesse aspecto, um exemplo da importância comercial deste produto, pode ser constatado através do relatório do Presidente da Província do Paraná, Zacarias de Góes e Vasconcelos, elaborado em 1854, o qual nos revela que "[...] a congonha e a criação absorvem a atenção e a atividade de grande maioria dos habitantes da província, aquela de ricos e de pobres [a erva-mate], esta dos homens abastados que possuem campos [a agropecuária]..." ${ }^{16}$ Em parte podemos explicar a popularidade desta atividade na época, pela facilidade de manejo desta cultura. Em outra passagem deste mesmo relatório, Góes e Vasconcellos nos dá um exemplo deste aspecto, acentuando as características de cultura extrativista da erva-mate: “[...] O mate, pois que é uma produção espontânea dos imensos ervais silvestres que cobrem uma dilatada extensão de território, está, como eu já disse, ao alcance da maior parte de sua população, sem distinção de sexo, nem de idade, pois que tanto as mulheres

13 OLIVEIRA, Ricardo Costa de. O silêncio dos vencedores: genealogia, classe dominante e Estado no Paraná. Curitiba: Moinho do Verbo, 2001. p. 70.

${ }^{14}$ Ibid., p.71.

${ }^{15} \mathrm{Id}$.

${ }^{16}$ PARANÁ. Governador. Relatório do Presidente da Província, Zacharias de Góes e Vasconcellos, na abertura da Assembléia Legislativa Provincial, Curitiba, 15 jul. 1854. p. 67. ARQUIVO PÚBLICO DO PARANÁ. Disponível em: <http://www.pr.gov.br/arquivopublico/pdf/rel_1854_a_p.pdf>. Acesso em: 20 nov. 2014. 
como os homens, assim os velhos como os meninos, são asados a trabalharem no seu primeiro e facílimo processo."17

A partir de 1870, com o término da construção da Estrada da Graciosa, permitindo a ligação entre o litoral e o planalto paranaense, contribuindo assim para a circulação e o desenvolvimento comercial entre essas localidades, inicia-se uma importante fase no ramo ervateiro. ${ }^{18}$ Neste âmbito, através do incremento dos meios de comunicação terrestres, houve condições mais propícias ao desenvolvimento dos engenhos de erva-mate, tanto em Curitiba, como em Campo Largo, considerado um lugar estrategicamente bem situado e provido de ervais. Em 1880 haveriam neste município, aproximadamente 11 proprietários de engenho de erva-mate, formando uma burguesia ervateira, fornecedora de importantes personagens para os quadros dirigentes do município. Figurando neste contexto, estariam as famílias Ribeiro de Macedo, Küster, Portella, Natel, Portugal, Vidal, Almeida Torres, Andrade, Oliveira e Souza, Miller, dentre outras. ${ }^{19}$

\section{OS DONOS DO PODER EM CAMPO LARGO}

Analisar a questão em relação aos donos do poder em Campo Largo, necessariamente devemos nos remeter a obra clássica do autor Raymundo Faoro, "Os donos do poder - formação do patronato político brasileiro" 20 , bem como a obra "Os herdeiros do poder, Francisco Antonio Doria. $^{21}$ Em Raimundo Faoro teríamos um diagnóstico preciso da origem do patrimonialismo brasileiro: a Casa de Aviz portuguesa no Século XIV. Naquele contexto, os reis de Portugal se consideravam proprietários do país e da nação, cultura que segundo Faoro atravessaria mares e séculos se enraizando com toda a força no Brasil e na concepção de Estado soberano. Em Doria poderíamos compreender que o uso do aparelho do Estado permitiria que a família se mantivesse na classe dominante, que ao seu ver, nada mais seria do que o conjunto daqueles que mandam, sendo a instituição do Estado um dos lócus mais importantes para que isso viesse a ocorrer. Caberia aqui

\footnotetext{
${ }^{17} \mathrm{Id}$.

${ }^{18}$ Ibid., p. 81.

${ }^{19}$ Ibid., p. 89.

${ }^{20}$ FAORO, Raimundo. Os donos do poder - formação do patronato político brasileiro. $3^{\text {a }}$ edição, revista, 2001.

${ }^{21}$ DORIA, Francisco Antonio. Os herdeiros do poder. Rio de Janeiro: Revan, 1994
} 
também colocarmos uma referência ao conceito de "elite política", que de acordo com Oliveira, ${ }^{22}$ se encontraria intimamente ligado a uma minoria politicamente ativa, que controlaria os processos de tomada de decisões de caráter político, em uma sociedade determinada. A elite política seria composta por uma seleção dos mais destacados e privilegiados atores políticos de uma configuração social que, por sua vez, ocupariam como demonstração de seu "status quo", importantes postos institucionais de caráter decisório e administrativo, como os ocupados no aparelho do Estado, representados pelas Câmaras Municipais e Prefeituras.

Nesses termos, observamos que da família Ribeiro de Macedo, tiveram participação efetiva neste processo, por ocasião de sua mudança do Porto de Cima para Campo Largo, os Coronéis Manoel Ribeiro de Macedo, Agostinho Ribeiro de Macedo e João Ribeiro de Macedo; a família Küster, com Antonio Carlos Küster; a família Almeida Torres, com o Coronel José de Almeida Torres, que já em 1856, investiu no beneficiamento da erva-mate, possuindo engenho hidráulico; a família Andrade, na pessoa de Joaquim Ribas de Andrade, residente no Quarteirão Guabiroba deste município, exercendo a profissão de comerciante e industrial de erva-mate, aproximadamente em 1908; a família Portella, na pessoa do senhor Osório Portella, proprietário de um engenho onde atualmente está localizada a Indústria Cerâmica Schmidt; a família Natel, na pessoa do senhor Francisco Custódio Natel; a família Portugal, na pessoa de Francisco Pinto de Azevedo Portugal, Francisco Pinto de Azevedo Portugal Filho e Jaime Pinto de Azevedo Portugal; a família Vidal, na pessoa de José de Paiva Vidal e Balduíno de Paiva Vidal, vindos de Cruz Alta, no Rio Grande do Sul; a família Oliveira e Souza, na pessoa do Capitão Carlos José de Oliveira e Souza, presidente da 3ํㅡㄹ Câmara Municipal de Campo Largo; a família Miller, na pessoa de José Mathias Miller, presidente da 4- Câmara Municipal. ${ }^{23}$

No ano de 2015, representantes da família Almeida Torres ainda fazem parte dos quadros políticos e empresarias da cidade, na figura de Luis Daniel Torres Júnior, eleito vereador pelo Partido Democratas para o mandato de 2013-2016, ocupando a $1^{\text {a }}$ Secretaria da Câmara Municipal de Campo Largo. Seu irmão, Jean Torres é presidente do Partido Democratas em Campo Largo, sócio proprietário da empresa Sabat Pub, casa de shows na cidade e proprietária da agência Megaideia. Outro irmão, Luiz Gustavo Torres, possui a empresa Luiz Gustavo Torres e Cia, do ramo de fornecimento de alimentos preparados para empresas. Seu pai, Luis Daniel Torres é Suplente de Delegado Regional no mesmo Partido e também assessor parlamentar do Deputado

\footnotetext{
${ }^{22}$ OLIVEIRA, 2001, p. 21-23.

${ }^{23}$ SOARES, op. cit., p. 361, 363 .
} 
Estadual Pedro Deboni Lupion Mello (DEM). Da família Vidal temos Bento Vidal, vice-presidente do Partido Democratas e também empresário do ramo imobiliário na cidade, com a empresa Bento Vidal Imobiliária. Seu irmão, Joel Henrique Vidal, faz parte do Conselho Consultivo do Democratas, e também possui a empresa Bar XV no município.

Outro aspecto que nos auxiliaria na identificação dos donos do poder em Campo Largo, seria o processo de imigração que este município apresentou no contexto social paranaense. Assim, uma importante fonte de informações neste sentido, pode ser encontrada nos relatórios apresentados pelos Presidentes da Província do Paraná à Assembléia Legislativa Provincial. Eles constituem fontes relevantes de informações sociais acerca do processo de imigração no Paraná, e de acordo com esta premissa, identificamos alguns núcleos coloniais no município de Campo Largo: colônia D. Pedro, fundada em julho de 1876, dispondo em 1879 de 23 famílias, destas, 69 indivíduos poloneses, prussianos e italianos; ${ }^{24}$ colônia Antonio Rebouças, fundada em setembro de 1878 sobre a Estrada Mato-Grosso, contando em 1879 com 35 famílias, num total de 151 indivíduos predominantemente italianos; ${ }^{25}$ núcleo ou colônia Santa Cristina, fundado em 1886 na presidência do Dr. Joaquim D `Almeida Faria Sobrinho, em terras lavradias compradas por conta do governo provincial do Paraná. Estas terras pertenciam a Casimiro de Souza Lobo e mediam $4.342 .932 \mathrm{~m}^{2}$, divididas em 59 lotes. Limitava-se ao Norte com terras dos herdeiros de José Ribeiro, Tenente Coronel Manoel Antonio de Andrade e Ferraz. Ao sul com terras de Nicolau Gonçalves Padilha e família Taborda. A Leste com terras da família Taborda, herdeiros de José Ribeiro e Ferraz. A Oeste com terras do Tenente Coronel Manoel Antonio de Andrade e Dona Brandina. Possuía em fins de 1886, 275 poloneses; colônia ou núcleo Alice, fundada na mesma data, em terras de lavoura doadas à Província do Paraná, pelo Dr. Alfredo d’ Escragnolle Taunay (Visconde de Taunay), medindo 639.927 braças quadradas, divididas em 9 lotes. Limitava-se ao Norte, com terras de Joaquim Pereira dos Santos, ao Sul e a Oeste, com terras de herdeiros de José Ribeiro, e a Leste com terras de Jacob Kastrop. Em 1886, esta colônia era composta por 33 habitantes. Em 1887 possuía 44 habitantes, todos poloneses. ${ }^{26}$ Teria contribuído para a viabilização destas colônias, dirigindo os trabalhos de implementação de vias de comunicação entre estes dois núcleos, o então Alferes João Ribeiro de Macedo, que na ocasião (ano de 1886), presidia a Sociedade de Imigração

24 PARANÁ. Governador (Menezes). Relatório do Dr. Rodrigo Otávio de Oliveira Menezes, passando a Presidência da Província ao Primeiro Vice-presidente Jesuíno Marcondes de Oliveira e Sá em 31 de março de 1879. p.49.

${ }^{25}$ Ibid., p. 52.

${ }^{26}$ Ibid., p. 22-23. 
de Campo Largo. Em 1888, teríamos a fundação da Colônia Mariana, possuindo uma área de 315 hectares dividida em 33 lotes, ocupados inicialmente por poloneses e brasileiros, e em seguida por italianos. $^{27}$

Com o advento da corrente imigratória para o Paraná, e mais especificamente para Campo Largo, houve um incremento na atividade econômica. Nesse sentido, as atividades desenvolvidas pelos imigrantes durante a República Velha (1889-1930) no Estado, podem ser descritas através do seguinte quadro:

\section{ATIVIDADES DESENVOLVIDAS PELOS IMIGRANTES}

\begin{tabular}{|l|l|}
\hline ETNIAS & ATIVIDADES PROFISSIONAIS \\
\hline Brasileiros & $\begin{array}{l}\text { Estabelecimentos ervateiros, casas de comissões, representações, consignações, } \\
\text { seguros e imobiliárias. }\end{array}$ \\
\hline Alemães & $\begin{array}{l}\text { Estabelecimentos industriais, como fábricas de tecidos de algodão, lã e meias, fitas e } \\
\text { metro, fósforos, tabletes alimentícios, sabão vidros, celulose e papel, adubos, } \\
\text { instrumentos musicais. }\end{array}$ \\
\hline Italianos & Indústria alimentícia, massas alimentares e fermentos, estabelecimentos comerciais. \\
\hline Poloneses & Agricultura, estabelecimentos comerciais. \\
\hline
\end{tabular}

FONTE: OLIVEIRA, 2001, p.125.

NOTA: O quadro mostra o predomínio das etnias em determinados ramos produtivos e comerciais, e não exclusividade sobre eles.

A presença destas etnias na economia da região daria origem à categoria social denominada "burguesia imigrante". Ricardo Costa de Oliveira, ${ }^{28}$ nos informa que este seguimento social já possuía uma experiência anterior em atividades comerciais e manufatureiras, detendo conhecimentos técnicos e um apurado senso perceptivo em relação às vantagens econômicas geradas pelos imigrantes, através de seus hábitos consumidores, ligados a alimentação, ao vestuário, aos utensílios domésticos e de trabalho, bem como às necessidades médicas e de transporte. Neste contexto, grande parte do sucesso dos empreendimentos iniciados pelos imigrantes, relacionar-se-ia

\footnotetext{
${ }^{27}$ BARBOSA, op. cit., p. 82.

${ }^{28}$ Ibid., p. 125.
} 
a rapidez com que se adaptavam à sociedade e a cultura que os antecedia na região, ou seja, à cultura tradicional brasileira, em seus aspectos econômicos, políticos e sociais. ${ }^{29}$

Esta adaptação exigiria do imigrante, um movimento de re-socialização, especialmente em relação ao conhecimento da língua portuguesa dominante, apesar da existência de multiplicidade étnica. O conhecimento da língua, portanto, veio facilitar não somente a comunicação, mas também a integração desta localidade, o que fazia com que imigrantes italianos, alemães, poloneses, entre outros, conseguissem interagir em um nível satisfatório. ${ }^{30}$ No município de Campo Largo, o período da imigração trouxe, além de outros, dois grupos étnicos predominantes: italianos e poloneses. Exercendo a princípio a agricultura, reuniam-se na maioria das vezes, em pequenas comunidades ao redor de Igrejas por eles mesmos construídas. Nesse sentido, especulamos que, além de motivações religiosas e educacionais, pela visualização da possibilidade de obter-se educação, através de párocos letrados, ${ }^{31}$ haveriam também motivações de ordem econômica. Um dos indícios que nos autorizaria a fazer esta afirmação, seria o número expressivo de estabelecimentos comerciais existentes em torno de Igrejas. Um exemplo desse aspecto, pode ser encontrado em torno da Igreja Nossa Senhora da Piedade, que manteve ao seu redor - algumas delas ainda em funcionamento -, casas comerciais das famílias Torres, Soviersoski, Barbosa e Puppi.

No cenário político de 2015, da família Puppi poderíamos citar Marcelo Fabiani Puppi, proprietário junto com seu filho Christiano Souto Puppi, da empresa Mp Comunicacao e Estrategia Ltda - ME. ${ }^{32}$ Marcelo F. Puppi é o Delegado Regional do Democratas em Campo Largo, e seu filho

\footnotetext{
${ }^{29}$ Ibid., p. 127.

${ }^{30}$ Nesse sentido, acredito ser válido dispor aqui a afirmação do senhor Reinaldo Pereira Vidal, lembrando algumas reminiscências, no tempo em que convivia com seus avós, os quais lhe contavam que, quando alguém queria comprar alguma coisa - seja este alguém italiano, alemão, ou polonês - diziam que estavam indo comprar no "Chico Polaco". Acreditamos que esse "Chico Polaco" seja o senhor Francisco Sovierzoski, então comerciante na época.(VIDAL, Reinaldo Pereira. Entrevista concedida a Vanderlei Hermes. Campo Largo, 06 fev. 2005.)

31 Algumas famílias possuíam recursos intelectuais para ensinarem seus próprios filhos em casa, mas outras necessitavam de estabelecimentos apropriados para isto. Um dos parcos depoimentos existentes sobre este aspecto nesta época, se encontra o da senhora Luiza Eulália Stroparo, com 91 anos em 1978, natural de Brusa Porco, diocese de Treviso, na Itália, nascida em $1^{\circ}$ de setembro de 1887 , sendo uma das primeiras moradoras fundadoras da Colônia Mariana em Campo Largo. Em seu relato, menciona: “... Vim da Itália com dois anos e meio, em 1890, fundando a Colônia Mariana, no município de Campo Largo.Ficamos com trinta famílias em barracões em Campo Largo, antes. Não estudei, porque não havia escola naquele tempo. Nem pagando, a gente encontrava professor. Aprendi a ler em italiano com minha mãe." (FEDALTO. O centenário da colônia Antonio Rebouças. Curitiba: Voz do Paraná, 1978. p. 202.)

${ }^{32}$ Marcelo Fabiani Puppi. Disponível em:<http://www.consultasocio.com/q/sa/marcelo-fabiani-puppi $>$. Acesso em:
} $05 / 04 / 2015$. 
é Tesoureiro do partido. ${ }^{33}$ foi vereador na gestão 2005-2008 pelo Partido Democratas, e candidato oficial as eleições para prefeito de Campo Largo em 2016. Seu avô, Domingos Puppi, foi comerciante na década de 1960 em Campo Largo. ${ }^{34}$ Participou das eleições municipais de 1958, como candidato a vereador pelo PDC, obtendo 112 votos, ficando como $2^{\circ}$ Suplente. Por ocasião da licença do vereador Oscar Chiquito, na data de 11 de julho de 1960, tomou posse como vereador, sendo eleito Presidente da Câmara Municipal, no dia 04 de dezembro de 1961. No dia 09 de abril de 1962, renunciou ao mandato de Vereador. Seu pai, Newton Luiz Guido Puppi nasceu em Campo Largo, no dia 06 de setembro de 1933. Casou-se com Roseli Fabiani Puppi, com quem teve 4 filhos. Advogado, aos 18 anos iniciou sua carreira como escriturário da Caixa Econômica Federal, tornando-se mais tarde gerente. Foi nomeado pelo Governador Emílio Hoffmann Gomes, através do Decreto $\mathrm{n}^{\mathrm{O}}$ 5.097, de 27 de fevereiro de 1974 para o cargo de Diretor do Departamento de Aplicação do Capital do IPE (Instituto de Previdência e Assistência aos Servidores do Estado). ${ }^{35}$ Participou das eleições municipais ocorridas em 1962, como candidato a prefeito pelo PDC, elegendo-se com 1977 votos. Disputou as eleições municipais de 15 de novembro de 1976, como candidato a prefeito pela ARENA, elegendo-se com 6.660 votos, para um período de mandato de 6 anos. Em outubro de 1982, renunciou ao mandato de prefeito. Newton Luiz Guido Puppi, também participou das eleições municipais de 1996, como candidato a prefeito pela coligação PTB/PSC/PL/PFL/PRN/PSB, elegendo-se com 26.274.

De acordo com Oliveira ${ }^{36}$ capitais sociais e econômicos trazidos pelos imigrantes, contribuiriam de forma essencial para o aparecimento de uma estruturação de classes. Baseada na diferenciação social entre eles, os levariam muitas vezes, a imitarem o familismo da velha classe dominante luso-brasileira, onde a parcela enriquecida destes, tenderia a reproduzir a sua posição de classe privilegiada. Em Campo Largo, poderíamos encontrar evidências deste fenômeno, tanto na esfera econômica, quanto política do município. Dentre as famílias imigrantes que apresentam esta característica, observando suas respectivas temporalidades de atuação, temos: Soviersoski, Puppi, Castagnolli, Andreassa, Pianaro, Zanlorenzi e Bassani.

\footnotetext{
${ }^{33}$ Ibid. Folha de Campo Largo.

${ }^{34}$ Como atestam os anúncios publicitários Domingos Puppi e Filho Ltda. e Puppi Magazin. (Folha de Campo Largo, 18 abr. 1965. p.04. Propaganda.)

${ }^{35}$ A Posse de Newton Puppi. O Liberal, Campo Largo, 10 mar. 1974. p.01.

${ }^{36}$ OLIVEIRA, 2001, p.128.
} 
No ano de 2015, o principal expoente político da família Andreassa é Darci Antonio Andreassa (PMDB-Partido do Movimento Democrático), eleito pela sétima vez. Pedro Ângelo Andreassa foi o iniciante da família na política, sendo vereador na década de 1960. Seu pai, Jerônimo Antonio Andreassa, fora comerciante em Campo Largo desde 1950, proprietário da empresa "Andreassa, Comércio de Cereais e Sacaria Ltda e Transportes". Darci Antonio Andreassa também foi comerciante, trabalhando com seu pai e iniciando sua vida pública em 1982, sendo eleito para seu primeiro mandato como vereador, com 807 votos pelo PMDB.

No ano de 1911, encontramos vários registros que atestam a presença comercial dessas famílias no município. Nesse contexto, identificamos Francisco e seu filho Lucas Soviersoski, possuindo cada qual o seu comércio, localizados na região central do município; ${ }^{37}$ Luiz Puppi (Luigi Puppi), imigrante italiano, também comerciante; ${ }^{38}$ Rodolpho Castagnolli, imigrante italiano, com mercado em São Luiz do Purunã; ${ }^{39}$ os irmãos Álvaro e Manoel de Paula Andrade, ambos com casa comercial no distrito de Bateias. ${ }^{40}$ Em 1912, temos Cezar Torres, estabelecido com Farmácia. ${ }^{41}$ Em 1914, encontramos Antonio Basso, proprietário de comércio no distrito de Bateias, ${ }^{42}$ e em 1916, Attílio de Almeida Barbosa, proprietário de Farmácia. ${ }^{43}$

Em 2015, temos Josley Natal Basso de Andrade e Edson Darlei Basso como principais protagonistas da família Basso Andrade no cenário político campolarguense. Josley foi eleito vereador pelo PSC - Partido Social Cristão - para o mandato 2013-2016. Em 2015 teríamos também a participação de Edson Darlei Basso, que fora prefeito de Campo Largo na gestão 20092012 pelo PMDB. Basso também é cotado como candidato ao cargo de prefeito municipal no ano de 2016, sendo desde 1979 proprietário da "Farmácia Basso". ${ }^{44}$

\footnotetext{
${ }^{37}$ CAMPO LARGO. Prefeitura Municipal. Prefeito (José de Sales Pinto). Lançamento dos nomes dos contribuintes dos impostos de comércio, mercado, indústria, oficinas diversas e terrenos do quadro urbano, obtidos sobre custas de datas não edificados e outros, para o exercício de 1911, 02 jan. 1911, p.01.

${ }^{38}$ Ibid., 29 mar. 1911, p.01.

${ }^{39}$ Ibid., 11 fev. 1911, p.02.

${ }^{40}$ Ibid., 13 fev. 1911, p.02.

${ }^{41}$ Ibid., 30 mar.1912.

42 CAMPO LARGO. Prefeitura Municipal. Lançamento dos nomes dos contribuintes dos impostos de comércio, mercado e indústria, para o exercício de 1914.

${ }^{43}$ Ibid., 24 jul. 1916.

${ }^{44}$ ACICLA - Associação Comercial e Industrial de Campo Largo. Registro no 2059.
} 
A partir de 1920, quando a população do município, incluindo os distritos de Balsa Nova e São Luiz do Purunã, foi estimada em 4014 indivíduos, cerca de 2496 homens, destes 355 estrangeiros, e 1519 mulheres, destas 175 estrangeiras, ${ }^{45}$ constatamos a presença de outro membro da família Puppi, José Puppi, irmão de Luiz Puppi, como comerciante; ${ }^{46}$ Ainda este ano, identificamos a presença de Otalípio Pereira de Andrade, proprietário de casa comercial no distrito de Bateias. $^{47}$

Ao longo da década de 1930, outros personagens se fazem presentes no cenário econômico de Campo Largo, como Mauro Portugal, com seu estabelecimento farmacêutico na região central da cidade; ${ }^{48}$ Juvino Portugal, com casa comercial; ${ }^{49}$ José Spack, com sua alfaiataria; ${ }^{50}$ José Ribas Vidal, com casa comercial; ${ }^{51}$ Joaquim Ribas de Andrade e João Antonio Sávio, compradores de erva-mate, o primeiro estabelecido na localidade denominada Lagoa, e o segundo no centro da cidade ${ }^{52}$ Dados estatísticos do recenseamento feito em 1937 estimavam a população do município, em 19.300 indivíduos. ${ }^{53}$

Encontramos no ano de 1945, vários registros que confirmam a atuação das famílias participantes nos cenários político e econômico do município, como o de Carlos Jerônymo Zanlorenzi, com sua fábrica de vinhos, localizada na região do Guabiroba; ${ }^{54}$ Antonio Sávio, imigrante italiano, proprietário de fábricas de gasosa e vinho, padaria, e também comprador de

\footnotetext{
45 ANUÁRIO ESTATÍSTICO DO BRASIL. Rio de Janeiro: Tipografia do Departamento de Estatística e Publicidade,
} ano III, p. 278, 1920.

${ }^{46}$ CAMPO LARGO. Prefeitura Municipal. Lançamento dos nomes dos contribuintes dos impostos de comércio, mercado, indústria, 19 abr. 1921.

${ }^{47}$ Ibid., 27 fev. 1926.

${ }^{48}$ Ibid., 28 fev. 1933.

${ }^{49}$ Ibid., 03 fev. 1934.

${ }^{50}$ Ibid., 28 fev. 1931.

${ }^{51}$ Ibid., 29 abr. 1931.

${ }^{52}$ Ibid., 30 ago. 1933; 04 jan. 1935.

${ }^{53}$ ANUÁRIO ESTATÍSTICO DO BRASIL. Rio de Janeiro: Tipografia do Departamento de Estatística e Publicidade, ano III, p. 130, 1938.

${ }^{54}$ CAMPO LARGO. Prefeitura Municipal. Lançamento do imposto de indústria e profissões, para o ano de $1945, \mathrm{n}$. de ordem 75, p.02. 
fumo ${ }^{55}$ Antonio Vidal, com comércio de secos e molhados, no distrito de Três Córregos, ${ }^{56}$ Domingos Puppi, com fazenda de criação de gado ${ }^{57}$ Joaquim Ribas de Andrade, proprietário de fábrica de carvão, no bairro Guabiroba; ${ }^{58}$ José Ribas Vidal, com comércio de secos e molhados e vendas de cigarros, na região central da cidade. ${ }^{59}$ Em 1946, Joaquim Ribas de Andrade aparece como criador de gado, no distrito de São Luiz do Purunã, e como comerciante de lenha, estabelecido na rua XV de Novembro; ${ }^{60}$ Elias de Paiva Vidal, comércio de secos e molhados, armarinhos, na região central. ${ }^{61}$ Através de recenseamento feito em 1940, estimou-se a população total do município, em 22.549 indivíduos, destes, 2.195 na zona urbana, 19.593 na zona rural, e 761 residindo em vilas. ${ }^{62}$

Analisando alvarás de concessão de abertura de comércio e indústria, e o Livro de lançamento de impostos, no decorrer das décadas de 1950 e 1960, identificamos em 1956 a permissão para a Indústria Madeireira Pianaro Ltda, se estabelecer com depósito de madeira bruta e beneficiamento, ${ }^{63}$ em 1957, as permissões para José Spack, se estabelecer com casa comercial na rua Centenário; ${ }^{64}$ para João Andreassa, se estabelecer com Serraria, no bairro Bom Jesus ${ }^{65}$ para José Castagnoli, com casa de calçados, na rua Marechal Floriano, ${ }^{66}$ para Irmãos Wilsek, com

\footnotetext{
55 Ibid., n. de ordem 38, p.4.

${ }^{56}$ Ibid., n. de ordem 40, p.4.

${ }^{57}$ Ibid., n. de ordem 89, p.5.

${ }^{58}$ Ibid., n. de ordem 210, p.10.

${ }^{59}$ Ibid., n. de ordem 237, p.11.
}

${ }^{60}$ CAMPO LARGO. Prefeitura Municipal. Lançamento do imposto de indústria e profissões, para o ano de $1946, \mathrm{n}$. de ordem 205, p. 23.

${ }^{61}$ Ibid., n. de ordem 125, p. 71.

${ }^{62}$ ANUÁRIO ESTATÍSTICO DO BRASIL. Rio de Janeiro: Serviço Gráfico do Instituto Brasileiro de Geografia e Estatística, ano VIII, p. 67, 1947.

${ }^{63}$ CAMPO LARGO. Prefeitura Municipal. Livro de alvarás de concessão para abertura de estabelecimento comercial e industrial. Prefeitura Municipal de Campo Largo, 10 jan. 1956. Talão sob nº: 20.543.

${ }^{64}$ CAMPO LARGO. Prefeitura Municipal. Livro de alvarás de concessão para abertura de estabelecimento comercial e industrial. Prefeitura Municipal de Campo Largo, 14 maio 1957. Talão sob nํ: 28.977.

65 CAMPO LARGO. Prefeitura Municipal. Livro de alvarás de concessão para abertura de estabelecimento comercial e industrial. Prefeitura Municipal de Campo Largo, 30 out. 1958. Talão sob no: 6.230.

${ }^{66}$ Ibid., 21 jan. 1957. Talão sob nơ: 25.958. 
estabelecimento de açougue e fábrica de banha, no distrito de Bateias; ${ }^{67}$ em 1962, para Domingos Puppi e Filho Ltda, se estabelecer com casa comercial, situada na rua Marechal Deodoro; ${ }^{68}$ em 1964, para Amadeu Spack, se estabelecer com casa comercial, na rua Centenário; ${ }^{69}$ em 1965 para Orlando Schiavon e Cia Ltda, se estabelecer com fábrica de pedras para ariar fogão, situada na rua D. Pedro II. ${ }^{70}$ Segundo o recenseamento geral de $1^{\underline{o}}$ de setembro de 1960, Campo Largo apresentava uma população registrada de 32.272 pessoas, destas, 9.150 residindo na zona urbana, e 23.122 na zona rural. $^{71}$

Na década de 1970, no livro de lançamentos de impostos da indústria e do comércio, encontramos João Bassani Sobrinho, sendo proprietário de loja de louças e artigos para presentes,

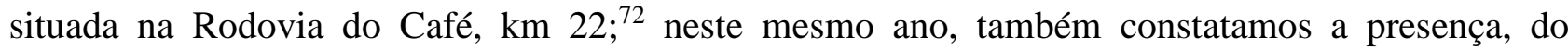
empreendimento denominado Sávio e Cia Ltda, Posto de Gasolina, lavagem e lubrificação de automóveis, situado na rua XV de Novembro, centro ${ }^{73}$ atuando no comércio de cereais, temos a empresa Irmãos Andreassa Ltda, localizada na Rodovia do Café, $\mathrm{km} 25 ;^{74}$ comercializando porcelanas, louças, vidros, plásticos e alumínio, temos a Distribuidora de Porcelanas Zanlorenzi Ltda, situada na rua Xavier da Silva, centro ${ }^{75}$ no ramo da panificação, encontramos a empresa Cavalli e Filhos Ltda, panificadora localizada na praça Attílio de Almeida Barbosa, centro; ${ }^{76}$ no comércio de ferragens e tecidos, identificamos a empresa Soviersoski Mercantil de Ferragem Ltda, centro $;{ }^{77}$ a atividade comercial da família Puppi em 1970, pode ser constatada através dos

\footnotetext{
${ }^{67}$ Ibid., 19 jan. 1957. Talão sob no: 25.951.

${ }^{73}$ Ibid., 06 maio 1970. Inscrição nº 121101.

${ }^{74}$ Ibid., 17 jun. 1970. Inscrição no 209102.

${ }^{75}$ Ibid., 04 ago. 1970. Inscrição nº 259102.

${ }^{76}$ Ibid., 05 ago. 1970. Inscrição no 261102.

${ }^{77}$ Ibid., 11 ago. 1970. Inscrição no 267102.
}

${ }^{68}$ CAMPO LARGO. Prefeitura Municipal. Livro de alvarás de concessão para abertura de estabelecimento comercial e industrial. Prefeitura Municipal de Campo Largo,19 out. 1962. Talão sob no: 16.663.

${ }^{69}$ CAMPO LARGO. Prefeitura Municipal. Livro de alvarás de concessão para abertura de estabelecimento comercial e industrial. Prefeitura Municipal de Campo Largo, 09 jul. 1964. Talão sob no: 6.838.

70 CAMPO LARGO. Prefeitura Municipal. Livro de alvarás de concessão para abertura de estabelecimento comercial e industrial. Prefeitura Municipal de Campo Largo, 24 ago. 1965. Talão sob no: 7.165.

${ }^{71}$ ANUÁRIO ESTATÍSTICO DO BRASIL. Rio de Janeiro: IBGE - Conselho Nacional de Estatística, ano XXIII, 1961.

72 CAMPO LARGO. Prefeitura Municipal. Livro de lançamento de impostos do comércio e indústria. Prefeitura municipal de Campo Largo, 25 mar. 1970. Inscrição no 070101. 
empreendimentos "Domingos Puppi e Filho Ltda", atuando no ramo de azulejos, cerâmicas, sanitários e metais, na Rodovia do Café, km 22, e "Puppi e Cia Ltda", comércio de eletro domésticos, roupas, calçados e ferragens, na rua Marechal Deodoro, centro; ${ }^{78}$ ainda em 1970, encontramos "Spack Veículos", importação e exportação, comércio varejista de veículos, peças e assessórios e prestação de serviços de oficina mecânica, lavagem, lubrificação e locação de veículos, sito a Rodovia Br 277, km 115,7; ${ }^{79}$ a "Farmácia Janguta", de Victor de Almeida Barbosa, situada na Rua Xavier da Silva, 1.252; ${ }^{80}$ em 1977, a loja de calçados "Chamego", de Sérgio Bassani ${ }^{81}$ em 1978, atuando no ramo comercial, constatamos a presença de João Fernando Vidal, com comércio de peças e acessórios, e reparação de veículos, localizado na Avenida Presidente Kennedy, centro, ${ }^{82} \mathrm{O}$ recenseamento feito neste ano mostrou um total de 39.868 pessoas residindo na cidade. ${ }^{83}$

Estes dados nos possibilitam confirmar em certa medida, a presença de alguns membros das famílias por nós analisadas, atuando também a partir da década de 1980. Dessa forma, constatamos registrada como prestadora de serviços na área de manutenção de automóveis, a empresa "Spack Spack", de Osmar e Sérgio Spack, fundada em 1983; ${ }^{84}$ com fundação em 1984, encontramos o comércio varejista de artigos de papelaria, denominado "Papelaria Sávio", de Dimas Roberto Sávio. ${ }^{85}$ Em 1985, a população residente em Campo Largo, foi estimada em 65.087 habitantes. ${ }^{86}$

A partir da década de 1990, identificamos o registro das empresas: "Posto Bassani", de propriedade de Atílio Bassani, em 1993; ${ }^{87}$ "Academia Alternativa Ltda", de propriedade de

\footnotetext{
${ }^{78}$ Ibid., 04 setembro de 1970. Inscrição no 313102 e 314102.

${ }^{79}$ Ibid., 17 de set. 1970. Inscrição no 334102.

${ }^{80}$ Ibid., 25 set. 1970. Inscrição no 381102.

${ }^{81}$ ACICLA - Censo econômico de Campo Largo. Registro no 1550.

${ }^{82}$ Ibid., 04 abr. 1978. Inscrição no 2016111.
}

${ }^{83}$ ANUÁRIO ESTATÍSTICO DO BRASIL. Brasília: Secretaria de Planejamento da República - Fundação Instituto Brasileiro de Geografia e Estatística, 1978.

${ }^{84}$ ACICLA - Cadastro de empresas, registro nํㅜ 568. novembro de 2002

${ }^{85}$ Ibid., registro no 2115 .

${ }^{86}$ ANUÁRIO ESTATÍSTICO DO BRASIL. Brasília: Secretaria do Planejamento da República - Fundação Instituto Brasileiro de Geografia e Estatística, 1985.

${ }^{87}$ ACICLA - Registro no 1319. 
Sebastião Torres, em 1995; ${ }^{88}$ a "Indústria e Comércio de Carnes Belvedere Ltda", cujos proprietários são Marcos Basso e Rosana Basso, em 1995;99 a "Bebidas Nova Geração Ltda", comércio varejista de bebidas, propriedade de Clayson Zanlorenzi, em 1995; ${ }^{90}$ a "Spack Lataria e Pintura", empresa de serviços de manutenção e reparação de automóveis, de propriedade de Pedro Spack, em 1998..$^{91}$ De acordo com o censo populacional de 1996, o município possuía uma população de 82.972 pessoas, destas, 41.717 homens, e 41.255 mulheres. ${ }^{92}$

Em 2001, pertencente a Ronaldo Basso e Direne Basso, identificamos a empresa denominada CEAGRO - Central de Insumos Agropecuários Campo Largo; ${ }^{33}$ a "Comércio de Gêneros Alimetícios Ltda", de propriedade de Aldamir Carlos Zanlorenzi; ${ }^{94}$ e em 2002, o "Auto Posto Jardim Guarani Ltda", cujo proprietário é Silvano Zanlorenzi. ${ }^{95}$ A população censitária total no ano de 2.000, de acordo com o IBGE é de 92.782 habitantes, com uma estimativa populacional para o ano de 2004, de 103.176 pessoas.

Outra família herdeira política no município de Campo Largo em 2015, se trata da família Beraldo, através do vereador Márcio Angelo Beraldo, eleito para o mandato 2013-2016 pelo PP Partido Progressista. Esta família teve sua primeira participação em cargo eletivo em 1920, através de Evangelista Beraldo, eleito vereador. Tendo também como cenário de atuação a Câmara Municipal de Campo Largo, encontramos a família Cavalin Cuba, através do vereador João Marcos Cavalin Cuba do PR - Partido da República (gestão 2013-2016). Esta família possui ramificações políticas no município que remontam a década de 1940. Neste mesmo contexto, teríamos a família Mocelin, através do vereador Dirceu Luiz Mocelin do PMDB. Esta família possui ligações políticas desde a decada de 1970, cujo vínculo maior se evidencia através do então prefeito Carlos Jerônymo Zanlorenzi (casado com Júlia Mocellin Zanlorenzi), que foi o fundador do MDB em Campo Largo.

\footnotetext{
${ }^{88}$ ACICLA - Registro no 1495.

${ }^{89}$ ACICLA - Registro no ${ }^{-1201 .}$

${ }^{90}$ ACICLA - Registro no 284.

${ }^{91}$ ACICLA - Registro no 533.

92 INSTITUTO BRASILEIRO DE GEOGRAFIA E ESTATÍSTICA. Censo demográfico: contagem da população nos municípios do Estado do Paraná, 1996.
}

${ }^{93}$ ACICLA - Registro no 1122.

${ }^{94}$ ACICLA - Registro nํㅜ 1044.

${ }^{95}$ ACICLA - Registro no 1341. 
Participou das eleições de 1972, como candidato a prefeito pelo MDB, elegendo-se com 6.190 votos. Dirceu Mocelin é empresário do ramo de supermercados em Campo Largo.

\section{CONSIDERAÇÕES FINAIS}

Nesta pequena contribuição elencamos alguns dos personagens que fazem parte da vida política e econômica de Campo Largo, sendo que muitos deles exercem papel preponderante nos rumos da cidade. Nossa pretensão limitou-se a descrição básica de alguns deles, mas que podem abrir caminhos para análises mais detalhadas e aprofundadas. São comerciantes, ervateiros, farmacêuticos, empresários do ramo de porcelanas, de mídias, prestadores de serviços, cartorários, entre outros, que figuram ou figuraram nos quadros políticos do município influenciando o andamento da sua dinâmica. Muitos deles são herdeiros econômicos e políticos, que trazem uma bagagem familiar moldada na tradição e ancestralidade de seus vínculos. Novos elementos ao longo do tempo vêm se somando a eles, absorvendo aprendizagens do cotidiano prático e teórico da política campolarguense. Talvez este seja um meio de continuarem no poder político de fato na cidade, em face de um poderio econômico já estabelecido no passado, muitas vezes durante o processo de imigração. Estas famílias dominam os partidos, principal meio regulador das eleições na cidade, uma vez que cabe a elas dirigir o processo eleitoral em importantes etapas, como a escolha de candidatos por exemplo. Analisar os donos do poder em Campo Largo, constitui uma tarefa que não pode prescindir de elementos do passado, pois eles se confundem com o presente, e provavelmente delinearão o futuro político e econômico da cidade.

\section{REFERÊNCIAS}

A Posse de Newton Puppi. O Liberal, Campo Largo, 10 mar. 1974.

ACICLA - Associação Comercial e Industrial de Campo Largo. Registro no 2059.

ANUÁRIO ESTATÍSTICO DO BRASIL. Rio de Janeiro: Tipografia do Departamento de Estatística e Publicidade, ano III, p. 278, 1920, 1938, 1978, 1995.

BARBOSA, João Augusto de Almeida. Campo Largo desde 1500. Campo Largo: Casa da Cultura, 1994.

CAMPO LARGO. Prefeitura Municipal. Lançamento dos nomes dos contribuintes dos impostos de comércio, mercado e indústria, para o exercício de 1914. 
CAMPO LARGO. Prefeitura Municipal. Prefeito (José de Sales Pinto). Lançamento dos nomes dos contribuintes dos impostos de comércio, mercado, indústria, oficinas diversas e terrenos do quadro urbano, obtidos sobre custas de datas não edificados e outros. 1911, 1921, 1946, 1956, 1957, 1958, 1962, 1964, 1965, 1970,

DORIA, Francisco Antonio. Os herdeiros do poder. Rio de Janeiro: Revan, 1994

FAORO, Raimundo. Os donos do poder - formação do patronato político brasileiro. 3.a edição, revista, 2001.

FEDALTO. O centenário da colônia Antonio Rebouças. Curitiba: Voz do Paraná, 1978. p.202.)

Folha de Campo Largo, 18 abr. 1965. p.04. Propaganda.

INSTITUTO BRASILEIRO DE GEOGRAFIA E ESTATÍSTICA. Censo demográfico: contagem da população nos municípios do Estado do Paraná, 1996.

POVOADO, LUGAREJO. In: MODERNO dicionário brasileiro. Curitiba: Ed. Educacional Brasileira, 1979. v.I..

BORBA, Oney Barbosa. Tropeirismo paranaense. Boletim do Instituto Histórico, Geográfico e Etnográfico Paranaense, Curitiba, v.XLVII, p. 107, 1990.

Marcelo Fabiani Puppi. Disponível em:<http://www.consultasocio.com/q/sa/marcelo-fabianipuppi>. Acesso em: 05/04/2015.

OLIVEIRA, Ricardo Costa de. O silêncio dos vencedores: genealogia, classe dominante e Estado no Paraná. Curitiba: Moinho do Verbo, 2001. p. 70.

PARANÁ. Governador. Relatório do Presidente da Província, Zacharias de Góes e Vasconcellos, na abertura da Assembléia Legislativa Provincial, Curitiba, 15 jul. 1854. p. 67. ARQUIVO PÚBLICO DO PARANÁ. Disponível <http://www.pr.gov.br/arquivopublico/pdf/rel_1854_a_p.pdf>. Acesso em: 20 nov. 2014.

PARANÁ. Governador (Menezes). Relatório do Dr. Rodrigo Otávio de Oliveira Menezes, passando a Presidência da Província ao Primeiro Vice-presidente Jesuíno Marcondes de Oliveira e Sá em 31 de março de 1879. 


\title{
THE POWER OF THE OWNERS IN CAMPO LARGO: WHO ARE THEY?
}

\begin{abstract}
The study aims to identify the main political and economic agents of the city of Campo Largo, PR, in the year 2015. Their genealogies, political and economic trajectories, make up the study to provide information for understanding the socio-political dynamics of this locality. "Power of owners in Campo Largo" also aims to assist the NEP - Core Paranaenses Studies - in the composition of a sociological collection on the Paraná, with respect to the characters of political, historical and economic life of this state.
\end{abstract}

Key-words: Campo Largo. Genealogy. Paranaense policy. 